\title{
Application of GC-MS for the detection of lipophilic compounds in diverse plant tissues
}

\author{
Anna Lytovchenko*1, Romina Beleggia², Nicolas Schauer ${ }^{1,6}$, Tal Isaacson ${ }^{3}$, \\ Jan E Leuendorf4, Hanjo Hellmann ${ }^{5}$, Jocelyn KC Rose ${ }^{3}$ and Alisdair R Fernie ${ }^{1}$
}

\begin{abstract}
Address: ${ }^{1}$ Max-Planck Institute of Molecular Plant Physiology, Am Muehlenberg 1, 14476 Potsdam-Golm, Germany, ${ }^{2}$ CRA Cereal Research Center, S.S. 16, km 675, 71100 Foggia, Italy, ${ }^{3}$ Department of Plant Biology, Cornell University, 331 Emerson Hall, Ithaca, New York 14853, USA, 4 Institute of Biology/Applied Genetics, Free University of Berlin, Albrecht-Thaer-Weg 6, 14195 Berlin, Germany, ${ }^{5}$ School of Biological Sciences, Washington State University, PO Box 644236 Pullman, WA 99164-4236, USA and 'Present address: De Ruiter Seeds, Leeuwenhoekweg 52, 2661CZ Bergschenhoek, the Netherlands

Email: Anna Lytovchenko* - lytovchenko@mpimp-golm.mpg.de; Romina Beleggia - romina.beleggia@entecra.it; Nicolas Schauer - schauer@europeanbiologists.com; Tal Isaacson - ti37@cornell.edu; Jan E Leuendorf - jodelhans@aol.com; Hanjo Hellmann - hellmann@wsu.edu; Jocelyn KC Rose - jr286@cornell.edu; Alisdair R Fernie - fernie@mpimp-golm.mpg.de

* Corresponding author
\end{abstract}

Published: 24 April 2009

Plant Methods 2009, 5:4 doi:10.1186/1746-48।I-5-4

This article is available from: http://www.plantmethods.com/content/5/l/4

(C) 2009 Lytovchenko et al; licensee BioMed Central Ltd.

This is an Open Access article distributed under the terms of the Creative Commons Attribution License (http://creativecommons.org/licenses/by/2.0), which permits unrestricted use, distribution, and reproduction in any medium, provided the original work is properly cited.
Received: 8 December 2008

Accepted: 24 April 2009

\begin{abstract}
Background: The concept of metabolite profiling has been around for decades and technical innovations are now enabling it to be carried out on a large scale with respect to the number of both metabolites measured and experiments carried out. However, studies are generally confined to polar compounds alone. Here we describe a simple method for lipophilic compounds analysis in various plant tissues.

Results: We choose the same preparative and instrumental platform for lipophilic profiling as that we routinely use for polar metabolites measurements. The method was validated in terms of linearity, carryover, reproducibility and recovery rates, as well as using various plant tissues.

As a first case study we present metabolic profiling of Arabidopsis root and shoot tissue of wild type (C24) and mutant (rsr4-I) plants deficient on vitamin B6. We found significant alterations in lipid constituent contents, especially in the roots, which were characterised by dramatic increases in several fatty acids, thus providing further hint for the role of pyridoxine in oxidative stress and lipid peroxidation.

The second example is the lipophilic profiling of red and green tomato fruit cuticles of wild type (Alisa Craig) and the DFD (delayed fruit deterioration) mutant, which we compared and contrasted with the more focused wax analysis of these plants reported before.

Conclusion: We can rapidly and reliably detect and quantify over 40 lipophilic metabolites including fatty acids, fatty alcohols, alkanes, sterols and tocopherols. The method presented here affords a simple and rapid, yet robust complement to previously validated methods of polar metabolite profiling by gas-chromatography mass-spectrometry.
\end{abstract}




\section{Background}

In the last few years gas-chromatography mass-spectrometry has become firmly established as a key technological platform for metabolite profiling in both plant and nonplant species [1-5]. Until relatively recently only a limited number of plant research laboratories had access to gaschromatography mass-spectrometry instrumentation, however, such machines are increasingly becoming more commonplace. The application of metabolite profiling is varied with studies ranging from the relative simplicity of diagnostics such as those used in herbicide mode-ofaction studies [6], or in blood plasma analysis [7] to the complexity inherent in integrative genomics and systems biology [8-10]. In the medicinal field the majority of studies have arguably been focussed on development of metabolite profiling as a diagnostic tool. In this field particularly impressive examples have been provided by the discovery of markers for coronary heart disease and atherosclerosis $[7,11]$. Although early plant studies also focussed in this area (see for example $[12,13]$ ), a great deal of research is currently carried out at a more mechanistic level often encompassing other post-genomic tools. Recent examples of note in this direction are the development of combined transcript-metabolite networks for aiding functional gene annotation $[14,15]$ and studies aimed at uncovering the genetic basis of metabolic regulation [16-20].

We have previously concentrated our own metabolite profiling activities on assessing the levels of polar primary metabolites of a wide range of species and tissues including potato (tuber and leaf), tomato (multiple tissues), strawberry (achene and receptacle), sunflower (stems), pea (embryo), medicago (roots) and cell suspension of the pennate diatom Phaeodactylum tricornutum [21-28]. Such measurements proved highly informative in addressing a range of questions such as defining the metabolic shifts underlying fruit development, quantifying the effects on metabolism in general of plants deficient in the expression of specific enzymes or metabolite transporters and in defining the cellular response of diatoms to iron availability.

Furthermore, our previous measurements were fully adequate for tissues, such as tomato pericarp or potato tuber, in which lipophilic components represent only a small proportion of the metabolome (when assessed on a per gram dry weight basis). However, for certain other tissues such as those of the oilseed plant Arabidopsis or specialised tissues such as the tomato fruit cuticle the data afforded by exclusive profiling of the polar metabolites are insufficient. For this reason we present here a simple yet validated and robust protocol for profiling the lipophilic components of methanol/chloroform extracts from Arabidopsis leaf and root and tomato fruit cuticles.
The developed method has the additional benefit that it is reliant merely on the machinery necessary for the profiling of the polar metabolites. It should be borne in mind that with this method we measure full lipid extracts, and as such, some of the measured derivatives are actually component parts of other physiological compounds, such as membrane or storage lipids or lipid conjugates. This fact notwithstanding, this method is likely to have high utility in detecting genotypes displaying altered lipophilic profiles. We present the range of linearity and reproducibility of the method, as well as document the recovery of authentic standards added prior to extraction in order to analyse their stability throughout the processes of extraction, derivatisation, injection and analysis. In addition we present two case studies, in which we compare the lipophilic profiles of different Arabidopsis and tomato genotypes and discuss the complementarity of the method with those that we routinely use.

\section{Results and discussion \\ Establishment of the method}

The method described here was used for detection of most abundant non-polar metabolites in Arabidopsis shoot and root and tomato fruit cuticles. We evaluated forty one compounds in terms of linearity, carryover and reproducibility, and the recovery of a subset of twenty seven of the compounds covering representatives of all major compound types was additionally carried out.

We chose to develop as simple a method as possible for the detection of major non-polar compounds in different plant tissues. For this reason we adopted the exact extraction procedure routinely used in our lab for polar compound analysis (see, for example, [21,29]), thus facilitating the preparation of both polar and apolar fractions at the same time from the exact same plant material. An aliquot of the chloroform fraction, which following our usual protocol would be discarded, was then used for further analysis using the same machine settings [21]. In addition we chose to use the same retention time (RT) standards mixture of alkanes, although only the later RT standards have high utility for the analysis of the plant tissues that we have evaluated to date (since only one compound is detected between the first and third RT standard). For the sake of simplicity we also refrained from the commonly used methyl esterification procedure for fatty acids. In doing so we avoided both a time consuming and potentially dangerous chemical reaction, and in our experience freshly extracted, rapidly vacuum concentrated extracts that are derivatised shortly before analysis, display a wide spectrum of fatty acid trimethylsilyl esters (TMS), which could be reproducibly detected in various tissues. 


\section{Validation of the method} Linearity

The linearity of the profiling method was assessed by analysis of standard compounds which were run in dilution series ranging from $1.25 \mathrm{ng}$ to $100 \mathrm{ng}$ of substance injected. The standard derivatisation protocol was used. Calibration curves were run both in ascending and descending direction, as well as completely randomised. For this purpose measurements were made in triplicate, response ratios relative to the internal standards nonadecanoic acid methyl ester were calculated, and for each metabolite the best linear correlation between response ratio and amount of the substance was determined and the linear correlation coefficient $\left(\mathrm{R}^{2}\right)$ was calculated (Table 1; Additional files 1, 2 and 3). The values for most metabolites were greater than 0.98 for the entire range of concentrations used. Exceptions were $\alpha$-tocopherol, octacosanoic acid, triacontanoic acid and $\alpha$-amyrin, for which the highest concentration (100 ng) had to be omitted from the calculation, and $\beta$ - and $\gamma$-tocopherol, for which two highest concentrations (50 ng and $100 \mathrm{ng}$ ) had to be omitted in order to achieve a good linear response. By contrast, for several metabolites, namely hentriacontane, tritriacontane, tetratriacontane and cholesterol the lowest amount (1.25 ng of substance injected) was excluded from the calculation.

\section{Reproducibility}

Both sample preparation procedure and instrumental analysis contribute to the variability of the method. The overall reproducibility of the method was tested by analysis of ten replicate extracts of $100 \mathrm{mg}$ of the same sample of Arabidopsis leaf (ecotype Col-0) or $50 \mathrm{mg}$ of red tomato cuticles (cultivar Alisa Craig) for assessment of behaviour of tocopherols and amyrins, where they were highly abundant. Samples were all run on the same day. Variability values (standard deviations) presented on a percent basis are listed in Table 1 . For most metabolites values were between 5 and 15\%, but for quarter of evaluated compounds they were slightly higher, between 15 and $20 \%$. These levels of variability are broadly in agreement with previously reported values for metabolite profiling protocols for a range of compound classes and instrumentation (see, for example, [21,30,31]).

\section{Recovery}

For the assessment of the extraction procedure and the chemical stability of the metabolites/derivatives recovery experiments were conducted. For this purpose double the amounts, present in the extract, of several authentic standard compounds were added at the beginning of extraction procedure to the tissue and recovery rates were calculated by running alongside unspiked extracts from the same biological sample. Given the prominence of Arabidopsis in genomics research we chose to perform these experi- ments in leaf tissue of this species (with exception of tocopherols and amyrins, for which red tomato cuticles were used). For all tested metabolites recovery values were in the range of $75-105 \%$ which is in close agreement with previous reports for polar metabolite determination via GC-MS (see, for example, [21])

To assess the applicability of the method for various plant tissues, recombination experiments were performed, in which aliquot of Arabidopsis leaf tissue was mixed with an aliquot of all other tissues and extracted in parallel with both tissues separately. Following analysis of these samples chromatograms were checked manually for possible peak shifts, for instances of peak co-elution and the appearance of new peaks, and the peak finding method was corrected accordingly as we have routinely done on optimisation of the polar method for novel tissues (see [32] for a detailed description).

\section{Carryover}

As a further validation we evaluated carryover rate which is noted as problematic for lipophilic compounds. For this purpose we assessed the peak area of each analyte in chromatograms of plant extract followed by blank injections (washes). These studies revealed that carryover was generally quite low with 31 of 41 compounds displaying carryover rate lower than 15\%, nine between 15 and $20 \%$ and only one compound (alkane $n$-tritriacontane) showed carryover rate of $21.8 \%$ [see Additional file 4].

As an initial case study we chose to analyse both leaf and root samples of an Arabidopsis mutant deficient in pyridoxine (Table 2). We have previously characterised this rsr4-1 mutant, which is deficient in vitamin B6 (pyridoxine) biosynthesis, as displaying broad alterations in metabolism with the levels of the polar metabolites of the amino acid and organic acid compound classes being most affected as well as the levels of raffinose and shikimate [33]. Given that the phosphorylated form of vitamin B6 is a co-factor not only in reactions associated with amino acid but also those associated with lipid degradation [34,35] and is furthermore believed to act as a protective agent against reactive oxygen species, such as singlet oxygen $[36,37]$, we thought it would be interesting to look at the lipophilic profiles of this mutant. With this aim in mind we harvested material from roots and leaves of six individuals from both the wild type and rs $r$-1 mutant. Although not reported in the previous manuscript, the roots of this mutant also displayed marked changes in amino acids (Lytovchenko A, Leuendorf JE, Hellmann H, Fernie AR, unpublished data). Intriguingly, the roots displayed massive alterations in their lipophilic profiles with 18 or the 22 metabolites measured exhibiting significantly increased levels and with some of these, such as eicosanoic acid and $\alpha$-tocopherol displaying in excess of 5-fold 
Table I: Method validation - linearity, reproducibility and recovery.

\begin{tabular}{|c|c|c|c|c|c|}
\hline Compound & $\mathrm{m} / \mathbf{z} \S$ & $\left.R\right|^{\#}$ & Linearity, $R^{2}$ & Reproducibility, \% variance & Recovery, \% \\
\hline n-Dodecane (CI2) (RT Standard I) & 85 & 1200 & & & \\
\hline n-Pentadecane (CI5) (RT Standard 2) & 85 & 1500 & & & \\
\hline n-Tetradecanoic acid (14:0) (TMS) & 242 & 1850 & 0.992 & 10.2 & nd \\
\hline n-Nonadecane (CI9) (RT Standard 3) & 85 & 1900 & & & \\
\hline n-Pentadecanoic acid (15:0) (TMS) & 299 & 1947 & 0.977 & 10.1 & nd \\
\hline n-Hexadecanol (IOH-I6:0) (TMS) & 299 & 1959 & 0.989 & 10.4 & 105 \\
\hline n-Hexadecenoic acid (16:1) (TMS) & 311 & 2021 & 0.994 & 19.6 & nd \\
\hline n-Hexadecanoic acid (16:0) (TMS) & 313 & 2047 & 0.981 & 6.8 & 97 \\
\hline n-Heptadecanoic acid (17:0) (TMS) & 327 & 2144 & 0.996 & 9.2 & nd \\
\hline n-Octadecanol (IOH-I8:0) (TMS) & 327 & 2154 & 0.991 & 7.1 & 102 \\
\hline n-Docosane (C22) (Rt Standard 4) & 85 & 2200 & & & \\
\hline n-9, I 2-Octadecadienoic acid (I 8:2) (TMS) & 337 & 2210 & 0.925 & 17.4 & nd \\
\hline n-Octadecenoic acid (1 8:I) (TMS) & 339 & 2215 & 0.999 & 13.2 & 75 \\
\hline n-Nonadecanoic acid methyl ester (IS) & 269 & 2232 & & & \\
\hline n-Octadecanoic acid (18:0) (TMS) & 341 & 2243 & 0.977 & 7.9 & 103 \\
\hline n-Eicosanol (TMS) (IOH-20:0) & 355 & 2362 & 0.998 & 5.9 & 91 \\
\hline n-Eicosenoic acid (20:1) (TMS) & 367 & 2401 & 0.995 & 14.7 & nd \\
\hline n-Eicosanoic acid (20:0) (TMS) & 369 & 2454 & 0.989 & 19.1 & 84 \\
\hline n-Docosanoic acid (22:0) (TMS) & 397 & 2649 & 0.996 & 15.6 & nd \\
\hline n-Heptacosane (C27) & 380 & 2708 & 0.976 & 7.7 & 97 \\
\hline n-Octacosane (C28) (Rt Standard 5) & 85 & 2800 & & & \\
\hline n-Tetracosanoic acid (24:0) (TMS) & 425 & 2838 & 0.994 & 14.7 & 77 \\
\hline$\delta$-tocopherol (TMS) & 474 & 2900 & 0.998 & 17.7 & 75 \\
\hline n-Nonacosane (C29) & 408 & 2902 & 0.983 & 12.2 & 96 \\
\hline n-Hexacosanol (TMS) (IOH-26:0) & 439 & 2945 & 0.985 & 5.1 & nd \\
\hline$\beta$-tocopherol (TMS) & 488 & 2987 & $0.999 a$ & 19.8 & 79 \\
\hline$\gamma$-tocopherol (TMS) & 488 & 2999 & $0.926^{a}$ & I4.I & 83 \\
\hline n-Triacontane (C30) & 422 & 3006 & 0.981 & 15.3 & 90 \\
\hline n-Hexacosanoic acid (26:0) (TMS) & 468 & 3037 & 0.925 & 9.7 & 91 \\
\hline n-Heptacosanol (TMS) (IOH-27:0) & 453 & 3043 & 0.986 & 10.9 & nd \\
\hline n-Hentriacontane (C3I) & 436 & 3105 & $0.964 b$ & 10.1 & 97 \\
\hline n-Octacosanol (TMS) (IOH-28:0) & 467 & 3139 & 0.985 & 11.9 & 88 \\
\hline$\alpha$-tocopherol (TMS) & 502 & 3143 & $0.998^{c}$ & 7.9 & 82 \\
\hline Cholesterol (TMS) & 458 & 3155 & $0.983^{b}$ & 13.3 & nd \\
\hline n-Dotriacontane (C32) (Rt Standard 6) & 85 & 3200 & & & \\
\hline n-Nonacosanol (TMS) (IOH-29:0) & 481 & 3236 & 0.917 & 6.7 & nd \\
\hline Campesterol (TMS) & 382 & 3263 & 0.989 & 6.9 & 102 \\
\hline n-Octacosanoic acid (28:0) (TMS) & 481 & 3269 & $0.977 \mathrm{c}$ & 10.5 & 83 \\
\hline Stigmasterol (TMS) & 484 & 3286 & 0.989 & 5.7 & 92 \\
\hline n-Tritriacontane (C33) & 464 & 3304 & $0.956 b$ & 9.1 & 91 \\
\hline n-Triacontanol (TMS) (IOH-30:0) & 495 & 3337 & 0.989 & 8.8 & nd \\
\hline$\beta$-Sitosterol (TMS) & 396 & 3344 & 0.997 & 8.1 & 90 \\
\hline$\delta$-amyrin (TMS) & 189 & 3375 & 0.993 & 19.1 & nd \\
\hline$\beta$-amyrin (TMS) & 498 & 3385 & 0.989 & 17.9 & 89 \\
\hline$n$-Triacontanoic acid (30:0) (TMS) & 509 & 3412 & $0.933^{c}$ & 19.2 & 76 \\
\hline$\alpha$-amyrin (TMS) & 498 & 3429 & $0.992^{c}$ & 15.5 & 80 \\
\hline n-Tetratriacontane (C34) & 478 & 3463 & $0.98 I^{b}$ & 18.2 & nd \\
\hline n-Dotriacontanol (TMS) (IOH-32:0) & 523 & 3533 & 0.967 & 9.9 & 98 \\
\hline n-Hexatriacontane (C36) (RT Standard 7) & 85 & 3600 & & & \\
\hline
\end{tabular}

nd - not determined; IS - internal standard

$\S$ specific mass ion used for quantification. Full spectrum information could be found at GMD database [55] and in Additional files I, 2 and 3 (for $\alpha$ amyrin, $\delta$-amyrin and $n$-eicosenoic acid)

\# relative retention index based on interpolation of retention times between alkane retention standards

a - range $1.25-25 \mathrm{ng}$ injected

b - range $6.25-100 \mathrm{ng}$ injected

c- range $1.25-50 \mathrm{ng}$ injected 
Table 2: Lipophilic metabolite contents in roots and shoots of agar-grown seedlings of rsr4-I Arabidopsis mutant.

\begin{tabular}{|c|c|c|}
\hline & $W T$ & rsr4-I \\
\hline \multicolumn{3}{|l|}{ Roots } \\
\hline | 4:0 & $1.00 \pm 0.05$ & $1.80 \pm 0.12$ \\
\hline 15:0 & $1.00 \pm 0.05$ & $1.79 \pm 0.09$ \\
\hline 16:0 & $1.00 \pm 0.04$ & $1.84 \pm 0.15$ \\
\hline 17:0 & $1.00 \pm 0.04$ & $1.87 \pm 0.12$ \\
\hline 18:0 & $1.00 \pm 0.05$ & $1.87 \pm 0.15$ \\
\hline 18:1 & $1.00 \pm 0.07$ & $2.19 \pm 0.19$ \\
\hline 20:0 & $1.00 \pm 0.06$ & $2.91 \pm 0.13$ \\
\hline 20:1 & $1.00 \pm 0.10$ & $8.08 \pm 0.35$ \\
\hline $22: 0$ & $1.00 \pm 0.06$ & $2.05 \pm 0.12$ \\
\hline $24: 0$ & $1.00 \pm 0.12$ & $3.07 \pm 0.19$ \\
\hline $26: 0$ & $1.00 \pm 0.11$ & $3.91 \pm 0.23$ \\
\hline $10 H-16: 0$ & $1.00 \pm 0.06$ & $1.65 \pm 0.14$ \\
\hline $1 \mathrm{OH}-18: 0$ & $1.00 \pm 0.06$ & $1.49 \pm 0.10$ \\
\hline $1 \mathrm{OH}-20: 0$ & $1.00 \pm 0.15$ & $1.58 \pm 0.19$ \\
\hline $1 \mathrm{OH}-28: 0$ & $1.00 \pm 0.21$ & $3.40 \pm 0.26$ \\
\hline $1 \mathrm{OH}-30: 0$ & $1.00 \pm 0.15$ & $3.72 \pm 0.27$ \\
\hline $\mathrm{C} 33$ & $1.00 \pm 0.12$ & $2.02 \pm 0.21$ \\
\hline C34 & $1.00 \pm 0.05$ & $1.68 \pm 0.14$ \\
\hline$\alpha$-tocopherol & $1.00 \pm 0.25$ & $5.90 \pm 0.27$ \\
\hline$\beta$-sitosterol & $1.00 \pm 0.12$ & $1.11 \pm 0.13$ \\
\hline campesterol & $1.00 \pm 0.15$ & $0.93 \pm 0.16$ \\
\hline stigmasterol & $1.00 \pm 0.16$ & $0.89 \pm 0.16$ \\
\hline \multicolumn{3}{|l|}{ Shoots } \\
\hline $14: 0$ & $1.00 \pm 0.07$ & $0.85 \pm 0.09$ \\
\hline $15: 0$ & $1.00 \pm 0.07$ & $0.87 \pm 0.06$ \\
\hline 16:0 & $1.00 \pm 0.07$ & $0.88 \pm 0.06$ \\
\hline $17: 0$ & $1.00 \pm 0.08$ & $0.85 \pm 0.07$ \\
\hline 18:0 & $1.00 \pm 0.06$ & $0.89 \pm 0.05$ \\
\hline 18:1 & $1.00 \pm 0.06$ & $0.93 \pm 0.10$ \\
\hline 18:2 & $1.00 \pm 0.14$ & $1.02 \pm 0.18$ \\
\hline 20:0 & $1.00 \pm 0.06$ & $0.94 \pm 0.07$ \\
\hline 20:1 & $1.00 \pm 0.06$ & $2.09 \pm 0.21$ \\
\hline $22: 0$ & $1.00 \pm 0.10$ & $0.80 \pm 0.09$ \\
\hline $24: 0$ & $1.00 \pm 0.02$ & $0.89 \pm 0.05$ \\
\hline $26: 0$ & $1.00 \pm 0.04$ & $0.94 \pm 0.04$ \\
\hline 28:0 & $1.00 \pm 0.06$ & $0.98 \pm 0.06$ \\
\hline $30: 0$ & $1.00 \pm 0.07$ & $0.96 \pm 0.06$ \\
\hline $1 \mathrm{OH}-16: 0$ & $1.00 \pm 0.07$ & $0.82 \pm 0.05$ \\
\hline $10 H-18: 0$ & $1.00 \pm 0.04$ & $0.91 \pm 0.05$ \\
\hline $10 \mathrm{H}-20: 0$ & $1.00 \pm 0.03$ & $0.92 \pm 0.05$ \\
\hline $1 \mathrm{OH}-26: 0$ & $1.00 \pm 0.10$ & $0.67 \pm 0.05$ \\
\hline $1 \mathrm{OH}-30: 0$ & $1.00 \pm 0.06$ & $0.72 \pm 0.08$ \\
\hline $1 \mathrm{OH}-32: 0$ & $1.00 \pm 0.07$ & $0.93 \pm 0.08$ \\
\hline $\mathrm{C} 27$ & $1.00 \pm 0.06$ & $0.99 \pm 0.05$ \\
\hline C34 & $1.00 \pm 0.14$ & $0.93 \pm 0.18$ \\
\hline$\alpha$-tocopherol & $1.00 \pm 0.04$ & $0.99 \pm 0.07$ \\
\hline$\beta$-tocopherol & $1.00 \pm 0.06$ & $0.94 \pm 0.05$ \\
\hline$\delta$-tocopherol & $1.00 \pm 0.06$ & $0.86 \pm 0.08$ \\
\hline$\beta$-sitosterol & $1.00 \pm 0.04$ & $1.00 \pm 0.06$ \\
\hline campesterol & $1.00 \pm 0.04$ & $1.02 \pm 0.06$ \\
\hline cholesterol & $1.00 \pm 0.03$ & $0.82 \pm 0.19$ \\
\hline stigmasterol & $1.00 \pm 0.07$ & $0.95 \pm 0.05$ \\
\hline
\end{tabular}

Values are expressed relative to wild type and presented as mean \pm $\mathrm{SE}$ of determinations from six independent samples. Those determined by the $\mathrm{t}$-test to be significantly different from wild type are set in bold type. increases. In the leaves of the mutant, the lipophilic components were, however, much more similar to those of the wild type with only three compounds (hexadecanol, hexacosanol and triacontanol) displaying altered levels in the mutant. In contrast to the situation seen in the leaves, in each instance the metabolite levels were decreased. That lipophilic metabolites are altered in the rsr4-1 mutant is not without precedence, since there is a long history of research of the role of pyridoxine on fatty acid metabolism. As early as 1952 it was suggested to be important for the linoleate to arachidonate conversion and it has also previously conversely been speculated that it could be involved in the catabolism of arachidonate [38]. However, there is to date no direct experimental evidence that confirms either of these postulates. Intriguingly, rats fed with a pyridoxine deficient diet (rats cannot synthesize the vitamin de novo but have an effective salvage pathway that converts pyridoxine to PLP), also have a tendency of increased unsaturated fatty acids [39]. In contrast, such rats have also been characterized to be deficient in galactolipids [40]. Despite these interesting observations, the only direct link between PLP and fatty acid biosynthesis appears to be its role in sphingolipid synthesis [41], although it is possible to speculate that some of the changes we observed are the consequence of a reduced rate of biotin biosynthesis, which is PLP- dependent [42], since the Acetyl CoA carboxylase is a biotin dependent enzyme [43]. However, as yet we have no evidence in support of this theory. Interestingly, the response of the lipophilic profiles of root and leaf of the rsr4 mutant were greatly different. The exact reasons underlying these differences are, however, not apparent from the present study. A recent study by Chen and Xiong [37] revealed, that the null mutant for the $p d x 1.3$ gene (which is allelic to $r s r 4$ ), was hypersensitive to UV treatment and other stresses, however, the authors did not measure the fatty acid content. It is conceivable, that the changes in the metabolic profile of the root were indicative of oxidative stress, however, we cannot exclude the fact that they may also be caused by developmental abnormalities in the roots. Whilst not allowing a precise mechanistic insight into this pathway, these data do provide highly interesting leads for future research.

As a second example we next evaluated the lipophilic content in enzymatically isolated cuticle tissue of both developing (green) and mature (red) fruits of Alisa Craig and the DFD (delayed fruit deterioration) mutant/accession of tomato. The levels of epicuticular waxes of these genotypes have previously been reported for these tissues of both genotypes [44]. Since the documented data was obtained using a different analytical method, we thought it would be highly interesting to evaluate this tissue using the method we developed here and to compare the results. For this purpose we evaluated cuticle preparation 
from fruits of five independent plants from both genotypes at both developmental stages. The changes in the absolute amounts of the various classes were fairly consistent between the studies, albeit far more of the changes observed were statistically significant in the current study. A further difference was that in the initial study there were no major differences in the individual wax constituent percentages suggesting little difference in their absolute amounts; however, in the data presented here there are significant changes in the relative levels of some but not all of the lipophilic compounds in each chemical class. Some of this discrepancy can clearly be explained by the fact that there is a general tendency for increases across the compound class, such as those observed for sterols and terpenoids, as well as for alkanes. However, for the fatty acids and fatty acid alcohols the differences in magnitude between the changes of independent members of each compound class are too great to account for the apparent discrepancy, suggesting that some of those may result from the differences in sample preparations.

In green fruit we determined the levels of 40 metabolites and found that 22 of these were significantly elevated in cuticles isolated from green fruit of the DFD mutant (Table 3).

Some of these changes were dramatic with over five fold increases in tetradecanoic, hexadecanoic, heptadecanoic, octadecanoic and hexacosanoic acids; as well as in nonacosanol, triacontanol, heptacosane and nonacosane; and over 13-fold increases in hexacosanol, heptacosanol and octacosanol. A similar picture was also obtained for the red fruit (Table 4), but in this case 37 of the 40 metabolites were significantly elevated, two unchanged and as previously commented on [44], one - naringenin chalcone decreased dramatically to levels below the detection limit. In this tissue it is quite possible that evaluating changes in \% composition masked some of the changes observed, but it is also worth noting that the standard errors associated with the previous method were also very high, which could additionally obscure changes. That said it must be stated, that several of the changes recorded here were dramatic with those in tetracosanoic acid, dotriacontanol, nonacosanol and $\alpha$-tocopherol being above tenfold, and in octacosanol, nonacosanol and triacontanol above 15 -fold. Of particular note is the massive change in $\alpha$-tocopherol content which could be of high potential interest for researchers interested in breeding high nutrient crops. Given the ease of compatibility of this method with previously described polar profiling methods, it may well prove highly useful in future biochemical characterisations of large mutant populations which are, by and large, reliant on simple and rapid screening methodologies.
Table 3: Lipophilic metabolite contents in green cuticles of DFD mutant and Alisa Craig wild type tomato.

\begin{tabular}{|c|c|c|}
\hline & WT green & DFD green \\
\hline \multicolumn{3}{|l|}{ Fatty acids } \\
\hline $14: 0$ & $1.00 \pm 0.29$ & $5.82 \pm 0.18$ \\
\hline 16:0 & $1.00 \pm 0.46$ & $6.68 \pm 0.16$ \\
\hline 17:0 & $1.00 \pm 0.44$ & $5.15 \pm 0.16$ \\
\hline 18:0 & $1.00 \pm 0.47$ & $5.04 \pm 0.17$ \\
\hline $18: 1$ & $1.00 \pm 0.24$ & $1.67 \pm 0.15$ \\
\hline 18:2 & $1.00 \pm 0.37$ & $1.70 \pm 0.18$ \\
\hline $20: 0$ & $1.00 \pm 0.24$ & $0.59 \pm 0.05$ \\
\hline $22: 0$ & $1.00 \pm 0.19$ & $1.65 \pm 0.13$ \\
\hline $24: 0$ & $1.00 \pm 0.23$ & $2.48 \pm 0.15$ \\
\hline $26: 0$ & $1.00 \pm 0.19$ & $5.68 \pm 0.12$ \\
\hline \multicolumn{3}{|c|}{ Fatty acid alcohols } \\
\hline $1 \mathrm{OH}-16: 0$ & $1.00 \pm 0.31$ & $1.13 \pm 0.24$ \\
\hline $1 \mathrm{OH}-18: 0$ & $1.00 \pm 0.18$ & $1.42 \pm 0.10$ \\
\hline $1 \mathrm{OH}-20: 0$ & $1.00 \pm 0.15$ & $3.43 \pm 0.11$ \\
\hline $1 \mathrm{OH}-26: 0$ & $1.00 \pm 0.16$ & $18.14 \pm 0.13$ \\
\hline $1 \mathrm{OH}-27: 0$ & $1.00 \pm 0.18$ & $17.64 \pm 0.09$ \\
\hline $1 \mathrm{OH}-28: 0$ & $1.00 \pm 0.27$ & $13.44 \pm 0.16$ \\
\hline $1 \mathrm{OH}-29: 0$ & $1.00 \pm 0.37$ & $8.91 \pm 0.09$ \\
\hline $1 \mathrm{OH}-30: 0$ & $1.00 \pm 0.39$ & $6.64 \pm 0.24$ \\
\hline $1 \mathrm{OH}-32: 0$ & $1.00 \pm 0.40$ & $2.71 \pm 0.12$ \\
\hline \multicolumn{3}{|l|}{ Alkanes } \\
\hline $\mathrm{C} 22^{\mathrm{a}}$ & $1.00 \pm 0.39$ & $3.61 \pm 0.30$ \\
\hline $\mathrm{C} 27$ & $1.00 \pm 0.27$ & $7.95 \pm 0.17$ \\
\hline $\mathrm{C} 28^{\mathrm{a}}$ & $1.00 \pm 0.12$ & $3.93 \pm 0.16$ \\
\hline $\mathrm{C} 29$ & $1.00 \pm 0.17$ & $6.04 \pm 0.12$ \\
\hline $\mathrm{C} 30$ & $1.00 \pm 0.23$ & $1.75 \pm 0.20$ \\
\hline C3I & $1.00 \pm 0.39$ & $3.03 \pm 0.20$ \\
\hline $\mathrm{C} 32^{\mathrm{a}}$ & $1.00 \pm 0.27$ & $3.97 \pm 0.71$ \\
\hline C33 & $1.00 \pm 0.35$ & $1.47 \pm 0.21$ \\
\hline \multicolumn{3}{|c|}{ Sterols and terpenoids } \\
\hline$\alpha$-amyrin & $1.00 \pm 0.25$ & $1.79 \pm 0.15$ \\
\hline$\beta$-amyrin & $1.00 \pm 0.33$ & $1.20 \pm 0.14$ \\
\hline$\delta$-amyrin & $1.00 \pm 0.19$ & $2.44 \pm 0.15$ \\
\hline$\beta$-sitosterol & $1.00 \pm 0.10$ & $1.84 \pm 0.14$ \\
\hline campesterol & $1.00 \pm 0.12$ & $1.63 \pm 0.12$ \\
\hline cholesterol & $1.00 \pm 0.10$ & $1.27 \pm 0.18$ \\
\hline multiflorenolb & $1.00 \pm 0.25$ & $1.31 \pm 0.16$ \\
\hline stigmasterol & $1.00 \pm 0.12$ & $1.15 \pm 0.14$ \\
\hline taraxasterolb & $1.00 \pm 0.24$ & $1.51 \pm 0.14$ \\
\hline$\alpha$-tocopherol & $1.00 \pm 0.22$ & $4.04 \pm 0.28$ \\
\hline$\beta$-tocopherol & $1.00 \pm 0.19$ & $2.24 \pm 0.20$ \\
\hline$\gamma$-tocopherol & $1.00 \pm 0.19$ & $2.52 \pm 0.17$ \\
\hline$\delta$-tocopherol & $1.00 \pm 0.23$ & $1.12 \pm 0.09$ \\
\hline
\end{tabular}

Values are expressed relative to wild type and presented as mean \pm $\mathrm{SE}$ of determinations from six independent samples. Those determined by the $t$-test to be significantly different from wild type are set in bold type.

a were determined in a parallel separate run without retention time standards mixture

${ }^{b}$ were identified according to [52] 
Table 4: Lipophilic metabolite contents in red cuticles of DFD mutant and Alisa Craig wild type tomato.

\begin{tabular}{|c|c|c|}
\hline & WT red & DFD red \\
\hline \multicolumn{3}{|l|}{ Fatty acids } \\
\hline $14: 0$ & $1.00 \pm 0.18$ & $4.34 \pm 0.12$ \\
\hline $15: 0$ & $1.00 \pm 0.16$ & $5.97 \pm 0.14$ \\
\hline $16: 0$ & $1.00 \pm 0.24$ & $4.07 \pm 0.32$ \\
\hline $17: 0$ & $1.00 \pm 0.10$ & $1.76 \pm 0.04$ \\
\hline $18: 0$ & $1.00 \pm 0.21$ & $2.64 \pm 0.31$ \\
\hline $18: 1$ & $1.00 \pm 0.37$ & $2.27 \pm 0.20$ \\
\hline $18: 2$ & $1.00 \pm 0.09$ & $5.96 \pm 0.07$ \\
\hline $20: 0$ & $1.00 \pm 0.21$ & $1.34 \pm 0.16$ \\
\hline $22: 0$ & $1.00 \pm 0.10$ & $8.95 \pm 0.19$ \\
\hline $24: 0$ & $1.00 \pm 0.12$ & $13.10 \pm 0.15$ \\
\hline \multicolumn{3}{|l|}{ Fatty acid alcohols } \\
\hline $10 \mathrm{H}-16: 0$ & $1.00 \pm 0.07$ & $3.57 \pm 0.22$ \\
\hline $1 \mathrm{OH}-18: 0$ & $1.00 \pm 0.09$ & $2.30 \pm 0.15$ \\
\hline $1 \mathrm{OH}-20: 0$ & $1.00 \pm 0.05$ & $4.38 \pm 0.29$ \\
\hline $1 \mathrm{OH}-26: 0$ & $1.00 \pm 0.11$ & $8.95 \pm 0.21$ \\
\hline $1 \mathrm{OH}-28: 0$ & $1.00 \pm 0.08$ & $16.23 \pm 0.13$ \\
\hline $\mathrm{IOH}-29: 0$ & $1.00 \pm 0.10$ & $15.52 \pm 0.12$ \\
\hline $\mathrm{IOH}-30: 0$ & $1.00 \pm 0.10$ & $22.53 \pm 0.13$ \\
\hline $1 \mathrm{OH}-32: 0$ & $1.00 \pm 0.14$ & $10.53 \pm 0.18$ \\
\hline \multicolumn{3}{|l|}{ Alkanes } \\
\hline $\mathrm{C} 22^{\mathrm{a}}$ & $1.00 \pm 0.17$ & $3.96 \pm 0.10$ \\
\hline $\mathrm{C} 27$ & $1.00 \pm 0.08$ & $7.09 \pm 0.24$ \\
\hline $\mathrm{C} 28^{\mathrm{a}}$ & $1.00 \pm 0.12$ & $4.69 \pm 0.18$ \\
\hline $\mathrm{C} 29$ & $1.00 \pm 0.08$ & $12.00 \pm 0.1 \mid$ \\
\hline $\mathrm{C} 30$ & $1.00 \pm 0.11$ & $6.56 \pm 0.15$ \\
\hline C3I & $1.00 \pm 0.12$ & $7.49 \pm 0.16$ \\
\hline $\mathrm{C} 32^{\mathrm{a}}$ & $1.00 \pm 0.14$ & $4.01 \pm 0.05$ \\
\hline $\mathrm{C} 33$ & $1.00 \pm 0.15$ & $2.76 \pm 0.18$ \\
\hline \multicolumn{3}{|c|}{ Sterols and terpenoids } \\
\hline$\alpha$-amyrin & $1.00 \pm 0.09$ & $5.42 \pm 0.13$ \\
\hline$\beta$-amyrin & $1.00 \pm 0.08$ & $4.02 \pm 0.12$ \\
\hline$\delta$-amyrin & $1.00 \pm 0.07$ & $5.53 \pm 0.13$ \\
\hline$\beta$-sitosterol & $1.00 \pm 0.12$ & $8.52 \pm 0.09$ \\
\hline campesterol & $1.00 \pm 0.10$ & $8.79 \pm 0.08$ \\
\hline cholesterol & $1.00 \pm 0.09$ & $6.17 \pm 0.17$ \\
\hline multiflorenolb & $1.00 \pm 0.06$ & $5.13 \pm 0.11$ \\
\hline naringenin-chalcone ${ }^{b}$ & $1.00 \pm 0.56$ & nd \\
\hline stigmasterol & $1.00 \pm 0.10$ & $4.20 \pm 0.11$ \\
\hline taraxasterolb & $1.00 \pm 0.07$ & $6.18 \pm 0.12$ \\
\hline$\alpha$-tocopherol & $1.00 \pm 0.12$ & $12.25 \pm 0.29$ \\
\hline$\beta$-tocopherol & $1.00 \pm 0.12$ & $5.62 \pm 0.08$ \\
\hline$\gamma$-tocopherol & $1.00 \pm 0.15$ & $6.10 \pm 0.19$ \\
\hline$\delta$-tocopherol & $1.00 \pm 0.25$ & $4.97 \pm 0.24$ \\
\hline
\end{tabular}

Values are expressed relative to wild type and presented as mean \pm $\mathrm{SE}$ of determinations from six independent samples. Those determined by the t-test to be significantly different from wild type are set in bold type.

${ }^{a}$ were determined in a parallel separate run without retention time standards mixture

${ }^{\mathrm{b}}$ were identified according to [52]

\section{Conclusion}

The method presented here affords a simple and rapid yet robust complement to previously validated methods of polar metabolite profiling by gas-chromatography massspectrometry. Given the high turnover rates of metabolites, it is imperative that methods are developed in a way that clearly demonstrates and documents their analytic precision [45]. The method presented here is generally similar to that published for potato metabolomics during the course of our study [30]. Whilst the potato study covers a slightly different range of metabolites than ours, the general analytic performance of the techniques is by and large comparable. Taking all our data into account, we conclude that we can rapidly and reliably detect and quantify over 40 lipophilic metabolites including fatty acids, fatty alcohols, alkanes and lipophilic vitamins. Whilst there has been much recent focus on standards initiatives in metabolomics [46,47], relatively few studies tackle the issues of metabolite stability through the extraction, derivatisation and analytical processes [48]. Here we have provided recoveries across the specific compound classes measured as well as confirming peak identification in the different samples via mixing or "recombination" experiments. These experiments revealed that the method was appropriate for the four tissues described here; however, we caution that such experiments should be empirically repeated for each new tissue analysed. In applying the method to two previously studied genotypes we were able to confirm its validity, as well as to extend the biochemical characterisation of these genotypes. The study on tomato cuticles has been largely consistent with the previous evaluations of this tissue using other analytical techniques $[44,49]$. That on the rsr $4-1$ mutant of Arabidopsis, however, provided novel data revealing comprehensive changes in the lipophilic profiles consistent with the suggested role of PLP both as a co-factor in lipid degradation and in the cellular response to oxidative stress. As such these case studies highlight the general utility of this method in expanding our coverage of the small molecular weight metabolome of plants.

\section{Methods \\ Plant material \\ Arabidopsis}

Arabidopsis 7-day-old seedlings of wild type (C24) and mutant (rsr4-1) plants [33] were grown under sterile conditions on vertically positioned agar plates containing basic Ats medium [50] without additional supplementation of sucrose. Plants were grown in a 16:8 day: night rhythm at 20 degrees Celsius using Phillips TLD 36W 1/ 830 light bulbs $\left(150 \mu \mathrm{mol}^{*} \mathrm{~m}^{-2}{ }^{*} \mathrm{~s}^{-1}\right.$ PAR at height of the growing seedlings). After $7 \mathrm{~d}$ plants were carefully removed from plates $8 \mathrm{~h}$ after light onset. Shoot and root tissues were separated from each other with a scalpel and immediately weighted on a Sartorius LE224S fine scale 
(Sartorius AG Göttingen). For metabolic analysis, between 100-150 mg and 50-100 mg of tissue were harvested for C24 and rsr4-1, respectively. Samples were immediately shock frozen in liquid nitrogen. Results are based on six independent samples.

\section{Tomato}

Tomato fruits were grown and harvested at the mature green and red ripe stages as described in [44]. Cuticles were enzymatically isolated [51] from tomato fruit exocarp discs by incubating at $32^{\circ} \mathrm{C}$ in mixture of cellulose $(40 \mathrm{U} / \mathrm{ml})$ and pectinase $(10 \mathrm{U} / \mathrm{ml})$ in sodium citrate buffer $(50 \mathrm{mM}, \mathrm{pH} 4.0), 1 \mathrm{mM} \mathrm{NaN}_{3}$ for 7 to 10 days. Cuticles were washed in distilled water and incubated again in the enzymatic buffer until clean. Cuticles were then washed in distilled water and dried at room temperature.

\section{Chemicals}

All chemicals and pure standard compounds were purchased from Sigma-Aldrich (Deisenhofen, Germany), with exception of trans-9-hexadecenoic acid, campesterol, $\beta$-sitosterol and stigmasterol, which were from Biotrend (Cologne, Germany) and N-Methyl-N-(trimethylsilyl)trifluoroacetamide (MSTFA) from Macherey-Nagel (Dueren, Germany). Solvents were of liquid chromatography grade and were supplied by Merck (Darmstadt, Germany).

\section{Extraction and derivatisation of the samples}

Extraction and derivatisation of the plant samples were done essentially as in [29], with exception that different volumes of solvents were used according to the fresh weight of the samples, and different aliquots of non-polar (chloroform) phase were taken for derivatisation. Briefly, Arabidopsis shoots (about $100 \mathrm{mg}$ fresh weight) and roots (about $70 \mathrm{mg}$ fresh weight) were homogenized and extracted in $1400 \mu \mathrm{l}$ of $100 \%$ methanol with addition of $60 \mu \mathrm{l}$ of nonadecanoic acid methyl ester (internal quantitative standard, $0.2 \mathrm{mg} \mathrm{ml}^{-1}$ stock in chloroform) at $70^{\circ} \mathrm{C}$ for $15 \mathrm{~min}$, then centrifuged, supernatant transferred to glass vial and double distilled water $(1000 \mu \mathrm{l})$ and chloroform $(1000 \mu \mathrm{l})$ were added, tubes were vigorously shaked and centrifuged. Aliquots of $400 \mu \mathrm{l}$ chloroform phase for shoots and roots were dried in speed-vac and derivatised afterwards. Tomato fruit cuticles (20-50 mg dry weight) were homogenized with pestle and mortar and extracted in $3000 \mu \mathrm{l}$ of methanol, $1000 \mu \mathrm{l}$ of water and $2000 \mu \mathrm{l}$ of chloroform with $60 \mu \mathrm{l}$ of nonadecanoic acid methyl ester. Aliquots of $1200 \mu \mathrm{l}$ of non-polar phase were dried and used for further analysis.

For derivatisation $70 \mu \mathrm{l}$ of MSTFA reagent for Arabidopsis shoots, $35 \mu \mathrm{l}$ for roots and $50 \mu \mathrm{l}$ for tomato cuticles together with $12 \mu \mathrm{l}$ of retention time standards mixture (alkanes dissolved in pyridine (see Table 1, Standards 1 and 2 - $2 \mu \mathrm{l}$ per ml stock, Standards 3-7 2 mg per ml stock, then mixed in equal amounts) were added and incubated at $37^{\circ} \mathrm{C}$ for $30 \mathrm{~min}$. As alternatives, fatty acid methyl esters (FAMEs) or isotope labelled retention time markers could also be used [see, for example, [12,29]]. All reagents and retention time standards were used routinely for both polar and non-polar phase analysis.

\section{Linearity experiment}

Linearity of the response of different amounts of metabolites was checked by injection of dilution series of standard compounds dissolved in chloroform (usually $1 \mathrm{mg}$ $\mathrm{ml}^{-1}$ stock). The amounts of all metabolites tested were $1.25,6.25,12.5,25,50$ and 100 ng of each injected substance.

\section{Reproducibility experiment}

Ten aliquots of approximately $100 \mathrm{mg}$ of Arabidopsis (Col-0) leaf tissue (the same pooled frozen material) were extracted and run at the same day. For the evaluation of amyrins and tocopherols tomato (cv. Alisa Craig) red cuticle tissue aliquots (50 mg) was used.

\section{Recovery experiment}

For estimation of efficiency of extraction procedure, the recovery rates of various metabolites were determined. To this end concentrations of endogenous compounds were determined in $100 \mathrm{mg}$ of Arabidopsis leaf tissue (for recovery of amyrins and tocopherols tomato (cv. Alisa Craig) red cuticle tissue was used, $50 \mathrm{mg}$ ) and then double amounts of standard compounds were added at the start of extraction procedure.

\section{Carryover experiment}

Carryover rate was determined for each individual metabolite measured. For this purpose we assessed the peak areas of each analyte in the chromatograms of plant extract followed by blank injections of MSTFA. For statistical analysis at least 3 replicates were used.

\section{GC-MS analysis}

Sample analysis was performed essentially as described in [21] with the exception of the column used (suitable both for polar and non-polar fraction analysis). Briefly, sample volumes of $1 \mu$ were injected with a split ratio of 25:1 using a hot-needle technique. The GC-MS system consisted of an AS 2000 autosampler, a GC 8000 gas chromatograph and a Voyager quadrupole mass spectrometer (ThermoQuest, Manchester, UK). Gas chromatography was performed on a $30 \mathrm{~m}$ capillary column Rtx-5Sil MS of $0.25 \mathrm{~mm}$ inner diameter with integrated guard column and a $0.25 \mu \mathrm{m}$ film (Restek GmbH, Bad Homburg, Germany). Injection temperature was $230^{\circ} \mathrm{C}$, the interface set to $250^{\circ} \mathrm{C}$ and the ion source adjusted to $200^{\circ} \mathrm{C}$. The carrier gas used was helium set at a constant flow rate of 1 
$\mathrm{mlmin}^{-1}$. The temperature program was $5 \mathrm{~min}$ isothermal heating at $70^{\circ} \mathrm{C}$, followed by a $5^{\circ} \mathrm{C} \mathrm{min}^{-1}$ oven temperature ramp to $310^{\circ} \mathrm{C}$ and a final 1 min heating at $310^{\circ} \mathrm{C}$. The system was then temperature equilibrated for $6 \mathrm{~min}$ at $70^{\circ} \mathrm{C}$ prior to injection of the next sample. Mass spectra were recorded at two scans per sec with an $\mathrm{m} / z$ 50-600 scanning range. The chromatograms and mass spectra were evaluated using the Masslab software (ThermoQuest, Manchester, UK).

\section{Data analysis}

Specific ions characteristic of each metabolite were selected and time windows were defined relative to an adjacent retention time standards for compound detection in processing methods created using Masslab. Processed data were checked manually and corrected when necessary before subjecting to further data analysis. Compounds were identified by using standard substances analysis, comparison with MS libraries and literature data (for example, [52-55]) and by extrapolation from data for known compounds (for example, for alkanes which have very characteristic and similar spectra). Processed data were subjected to statistical analysis (the term significant is used only when $\mathrm{p}<0.05$ according to the $t$-test embedded in Excel).

\section{Competing interests}

The authors declare that they have no competing interests.

\section{Authors' contributions}

$\mathrm{AL}$ and $\mathrm{RB}$ carried out the experimental work with support from NS, TI and JEL. ARF, HH and JKCR conceived the study and devised the experimental design. AL and ARF wrote the manuscript. All authors read and approved the final manuscript.

\section{Additional material}

\section{Additional File 1}

$\alpha$-amyrin spectrum. The data provided represent the list of $m / z$ of $\alpha$ amyrin with absolute and relative intensities.

Click here for file

[http://www.biomedcentral.com/content/supplementary/17464811-5-4-S1.xls]

\section{Additional File 2}

$\delta$-amyrin spectrum. The data provided represent the list of $\mathrm{m} / \mathrm{z}$ of $\delta$ amyrin with absolute and relative intensities.

Click here for file

[http://www.biomedcentral.com/content/supplementary/17464811-5-4-S2.xls]

\section{Additional File 3}

n-eicosenoic acid spectrum. The data provided represent the list of $\mathrm{m} / \mathrm{z}$ of $\mathrm{n}$-eicosenoic acid with absolute and relative intensities.

Click here for file

[http://www.biomedcentral.com/content/supplementary/17464811-5-4-S3.xls]

\section{Additional File 4}

Evaluation of carryover. The data provided represent estimation of carryover for each lipophilic compound from this study in percents.

Click here for file

[http://www.biomedcentral.com/content/supplementary/1746-

4811-5-4-S4.doc]

\section{Acknowledgements}

We would like to thank Maria Ines Zanor, Joachim Kopka, Alexander Erban and Ines Fehrle (all Max-Planck-Institute of Molecular Plant Physiology) for help and advises in GC-MS analysis. We are also greatly thankful to Lothar Willmitzer (same institute) for his long-term support and discussions. AL's research was in part supported by Deutsche Forschungsgemeinschaft (grant LY 88/I-I). Research support was provided to JKCR by the National Research Initiative of the USDA CSREES, grant number \# 2006-3530417323.

\section{References}

I. Robertson DG: Metabonomics in toxicology: A review. Toxicol Sci 2005, 85:809-822.

2. Fernie AR, Trethewey RN, Krotzky AJ, Willmitzer L: Innovation Metabolite profiling: from diagnostics to systems biology. Nat Rev Mol Cell Biol 2004, 5:763-769.

3. Kell DB, Brown M, Davey HM, Dunn WB, Spasic I, Oliver SG: Metabolic footprinting and systems biology: The medium is the message. Nat Rev Microbiol 2005, 3:557-565.

4. Fiehn O: Metabolomics - the link between genotypes and phenotypes. Plant Mol Biol 2002, 48: I 55- I7I.

5. Sumner LW, Mendes P, Dixon RA: Plant metabolomics: largescale phytochemistry in the functional genomics era. Phytochemistry 2003, 62(6):817-836.

6. Oikawa A, Nakamura Y, Ogura T, Kimura A, Suzuki H, Sakurai N, Shinbo $Y$, Shibata D, Kanaya S, Ohta D: Clarification of pathwayspecific inhibition by Fourier transform ion cyclotron resonance/mass spectrometry-based metabolic phenotyping studies. Plant Physiol 2006, I 42:398-4I3.

7. Brindle JT, Antti H, Holmes E, Tranter G, Nicholson JK, Bethell HWL, Clarke S, Schofield PM, McKilligin E, Mosedale DE, Grainger DJ: Rapid and noninvasive diagnosis of the presence and severity of coronary heart disease using H-I-NMR-based metabonomics. Nat Med 2002, 8: $1439-1444$.

8. Nicholson JK, Wilson ID: Understanding 'global' systems biology: Metabonomics and the continuum of metabolism. Nat Rev Drug Discov 2003, 2:668-676.

9. Carrari F, Baxter C, Usadel B, Urbanczyk-Wochniak E, Zanor MI, Nunes-Nesi A, Nikiforova V, Centero D, Ratzka A, Pauly M, Sweetlove LJ, Fernie AR: Integrated analysis of metabolite and transcript levels reveals the metabolic shifts that underlie tomato fruit development and highlight regulatory aspects of metabolic network behaviour. Plant Physiol 2006, 142:1380-1396.

10. Gibon Y, Usadel B, Blaesing OE, Kamlage B, Hoehne M, Trethewey R, Stitt $M$ : Integration of metabolite with transcript and enzyme activity profiling during diurnal cycles in Arabidopsis rosettes. Genome Biol 2006, 7(8):R76.

II. Lindon JC, Holmes E, Nicholson JK: Metabonomics: Systems biology in pharmaceutical research and development. Curr Opin Mol Ther 2004, 6:265-272. 
12. Fiehn O, Kopka J, Dormann P, Altmann T, Trethewey RN, Willmitzer $\mathrm{L}$ : Metabolite profiling for plant functional genomics. Nat Biotechnol 2000, I 8(I I): I I57-II6I.

13. Roessner U, Luedemann A, Brust D, Fiehn O, Linke T, Willmitzer Fernie AR: Metabolic profiling allows comprehensive phenotyping of genetically or environmentally modified plant systems. Plant Cell 200I, I3: I I-29.

14. Tohge T, Nishiyama Y, Hirai MY, Yano M, Nakajima J, Awazuhara M, Inoue E, Takahashi H, Goodenowe DB, Kitayama M, Noji M, Yamazaki $M$, Saito K: Functional genomics by integrated analysis of metabolome and transcriptome of Arabidopsis plants overexpressing an MYB transcription factor. Plant J 2005, 42:218-235

15. Saito K, Hirai MY, Yonekura-Sakakibara K: Decoding genes with coexpression networks and metabolomics - 'majority report by precogs'. Trends Plant Sci 2008, I 3:36-43.

16. Keurentjes J], Fu J, de Vos CH, Lommen A, Hall RD, Bino RJ, Plas LH van der, Jansen RC, Vreugdenhil D, Koornneef M: The genetics of plant metabolism. Nat Genet 2006, 38:842-849.

17. Schauer N, Semel Y, Roessner U, Gur A, Balbo I, Carrari F, Pleban T, Perez-Melis A, Bruedigam C, Kopka J, Willmitzer L, Zamir D, Fernie AR: Comprehensive metabolic profiling and phenotyping of interspecific introgression lines for tomato improvement. Nat Biotechnol 2006, 24:447-454.

18. Schauer N, Semel Y, Balbo I, Steinfath M, Repsilber D, Selbig J, Pleban T, Zamir D, Fernie AR: Mode of Inheritance of Primary Metabolic Traits in Tomato. Plant Cell 2008, 20:509-523.

19. Rowe HC, Hansen BG, Halkier BA, Kliebenstein DJ: Biochemical networks and epistasis shape the Arabidopsis thaliana metabolome. Plant Cell 2008, 20:1 199-1216.

20. Lisec J, Meyer RC, Steinfath M, Redestig H, Becher M, Witucka-Wall $\mathrm{H}$, Fiehn O, Torjek O, Selbig J, Altmann T, Willmitzer L: Identification of metabolic and biomass QTL in Arabidopsis thaliana in a parallel analysis of RIL and IL populations. Plant ] 2008, 53:960-972.

21. Roessner U, Wagner C, Kopka J, Trethewey RN, Willmitzer L: Simultaneous analysis of metabolites in potato tuber by gas chromatography-mass spectrometry. Plant J 2000, 23: I31-I42.

22. Lytovchenko A, Bieberich K, Willmitzer L, Fernie AR: Carbon assimilation and metabolism in potato leaves deficient in plastidial phosphoglucomutase. Planta 2002, 2 I 5:802-8I I.

23. Schauer N, Zamir D, Fernie AR: Metabolic profiling of leaves and fruit of wild species tomato: a survey of the Solanum lycopersicum complex. J Exp Bot 2005, 56:297-307.

24. Fait A, Hanhineva K, Beleggia R, Dai N, Rogachev I, Nikiforova VJ, Fernie AR, Aharoni A: Reconfiguration of the achene and receptacle metabolic networks during strawberry fruit development. Plant Physiol 2008, I 48:730-750.

25. Weigelt K, Kuster H, Radchuk R, Muller M, Weichert H, Fait A, Fernie $A R$, Saalbach I, Weber $H$ : Increasing amino acid supply in pea embryos reveals specific interactions of $\mathbf{N}$ and $\mathbf{C}$ metabolism, and highlights the importance of mitochondrial metabolism. Plant J 2008, 55(6):909-926.

26. Mazzella MA, Zanor MI, Fernie AR, Casal JJ: Metabolic responses to red/far-red ratio and ontogeny show poor correlation with the growth rate of sunflower stems. I Exp Bot 2008, 59(9):2469-2477.

27. Ruffel S, Freixes S, Balzergue S, Tillard P, Jeudy C, Martin-Magniette ML, Merwe MJ van der, Kakar K, Gouzy J, Fernie AR, Udvardi M, Salon C, Gojon A, Lepetit M: Systemic signaling of the plant nitrogen status triggers specific transcriptome responses depending on the nitrogen source in Medicago truncatula. Plant Physiol 2008, I 46:2020-2035.

28. Allen AE, LaRoche J, Maheswari U, Lommer M, Schauer N, Lopez PJ, Finazzi G, Fernie AR, Bowler C: Whole-cell response of the pennate diatom Phaeodactylum tricornutum to iron starvation. Proc Nat Acad Sci 2008, I 05: I 0438-10443.

29. Lisec J, Schauer N, Kopka J, Willmitzer L, Fernie AR: Gas chromatography mass spectrometry-based metabolite profiling in plants. Nature Protocols 2006, I:387-396.

30. Shepherd T, Dobson G, Verrall SR, Conner S, Griffiths DW, McNicol JW, Davies HW, Stewart D: Potato metabolomics by GC-MS: what are the limiting factors? Metabolomics 2007, 3:475-488.

31. Frenzel T, Miller A, Engel KH: Metabolite profiling - a fractionation method for analysis of major and minor compounds in rice grains. Cereal Chem 2002, 79:2I5-22I.
32. Roessner-Tunali U, Hegemann B, Lytovchenko A, Carrari F, Bruedigam C, Granot D, Fernie AR: Metabolic profiling of transgenic tomato plants overexpressing hexokinase reveals that the influence of hexose phosphorylation diminishes during fruit development. Plant Physiol 2003, I 33:84-99.

33. Wagner S, Bernhardt A, Leuendorf JE, Drewke C, Lytovchenko A, Mujahed N, Gurgui C, Frommer WB, Leistner E, Fernie AR, Hellmann $\mathrm{H}$ : Characterization of Arabidopsis thaliana rsr4-I/pdxI-3 and the pyridoxine synthase protein family. Plant Cell 2006, I 8: I722-1735.

34. Selvam $R$, Ravichandran V: Lipid peroxidation in liver of vitamin B6 deficient rats. I Nutr Biochem 1991, 2:245-250.

35. Kannan K, Jain SK: Effect of vitamin B6 on oxygen radicals, mitochondrial membrane potential, and lipid peroxidation in H2O2-treated U937 monocytes. Free Rad Biol Med 2004, 36:423-428.

36. Bilski P, Li MY, Ehrenshaft M, Daub ME, Chignell CF: Vitamin B6 (pyridoxine) and its derivatives are efficient singlet oxygen quenchers and potential fungal antioxidants. Photochem Photobiol 2000, 7 I: I29-I34.

37. Chen $\mathrm{H}$, Xiong LM: Pyridoxine is required for post-embryonic root development and tolerance to osmotic and oxidative stresses. Plant / 2005, 44:396-408.

38. Witten PW, Holman RT: Polyethenoid fatty acid metabolism .6. Effect of pyridoxine on essential fatty acid conversions. Arch Biochem Biophys 1952, 41:266-273.

39. Kirschman JC, Coniglio JG: The role of pyridoxine in the metabolism of polyunsaturated fatty acids in rats. J Biol Chem 196I, 236:2200-2203.

40. Stephens MC, Dakshinamurti K: Galactolipid fatty acids in brain of pyridoxine-deficient young rats. Exp Brain Res 1976, 25:465-468.

41. Hanada K: Serine palmitoyltransferase, a key enzyme of sphingolipid metabolism. Biochim Biophys Acta 2003, I 632:16-30.

42. Alban C, Job D, Douce R: Biotin metabolism in plants. Ann Rev Plant Physiol Plant Mol Biol 2000, 5 I : I7-47.

43. Waite M, Wakil SJ: Studies on mechanism of action of acetyl coenzyme A carboxylase .2. On mechanism of action of enzyme-bound biotin. J Biol Chem 1963, 238:81-90.

44. Saladié M, Matas AJ, Isaacson T, Jenks MA, Goodwin SM, Niklas KJ, Xiaolin R, Labavitch JM, Shackel KA, Fernie AR, Lytovchenko A, $O$ 'Neill MA, Watkins CB, Rose JKC: A reevaluation of the key factors that influence tomato fruit softening and integrity. Plant Physiol 2007, I 44:1012-1028.

45. Lee DY, Fiehn O: High quality metabolomic data for Chlamydomonas reinhardtii. Plant Methods 2008, 4:7.

46. Fiehn O, Wohlgemuth G, Scholz M, Kind T, Lee DY, Lu Y, Moon S, Nikolau B: Quality control for plant metabolomics: reporting MSI-compliant studies. Plant J 2008, 53:69|-704.

47. Sansone SA, Schober D, Atherton HJ, Fiehn O, Jenkins H, RoccaSerra P, Rubtsov DV, Spasic I, Soldatova L, Taylor C, Tseng A, Viant MR: Metabolomics standards initiative: ontology working group work in progress. Metabolomics 2007, 3:249-256.

48. Kopka J, Fernie A, Weckwerth W, Gibon Y, Stitt M: Metabolite profiling in plant biology: platforms and destinations. Genome Biol 2004, 5: 109.

49. Mintz-Oron S, Mandel T, Rogachev I, Feldberg L, Lotan O, Yativ M, Wang Z, Jetter R, Venger I, Adato A, Aharoni A: Gene expression and metabolism in tomato fruit surface tissues. Plant Physiol 2008, |47:823-85 I.

50. Estelle MA, Somerville CR: Auxin resistant mutants of Arabidopsis with an altered morphology. Mol Gen Genet 1987, 206:200-206

5I. Schonherr J, Riederer M: Plant cuticles sorb lipophilic compounds during enzymatic isolation. Plant Cell Environ 1986, 9:459-466.

52. Bauer S, Schulte E, Thier HP: Composition of the surface wax from tomatoes - I. Identification of the components by GC/ MS. Eur Food Res Technol 2004, 21 9:223-228.

53. Bauer S, Schulte E, Thier HP: Composition of the surface wax from tomatoes - II. Quantification of the components at the ripe red stage and during ripening. Eur Food Res Technol 2004, 2 | 9:487-49|.

54. Bauer S: Die Zusammensetzung der Oberflächenwachse von Tomaten, Paprika und Auberginen. In PhD-Thesis University of Münster, Germany; 2002. 
55. Kopka J, Schauer N, Krueger S, Birkemeyer C, Usadel B, Bergmuller E, Dormann P, Weckwerth W, Gibon Y, Stitt M, Willmitzer L, Fernie AR, Steinhauser D: GMD@CSB.DB: the Golm Metabolome Database. Bioinformatics 2005, 21:1635-1638.

Publish with Bio Med Central and every scientist can read your work free of charge

"BioMed Central will be the most significant development for disseminating the results of biomedical research in our lifetime." Sir Paul Nurse, Cancer Research UK

Your research papers will be:

- available free of charge to the entire biomedical community

- peer reviewed and published immediately upon acceptance

- cited in PubMed and archived on PubMed Central

- yours - you keep the copyright

Submit your manuscript here:

http://www.biomedcentral.com/info/publishing_adv.asp
BioMedcentral 